\title{
Small Open Online Course com Professores do Ensino Médio: desafios para integrar REA nos materiais e atividades didáticas
}

\author{
Mara D. Mazzardo ${ }^{1}$, Ana M. J. F. Nobre ${ }^{2}$, Elena M. Mallmann ${ }^{3}$ \\ ${ }^{1}$ Doutoranda da Universidade Aberta (UAb) Portugal \\ ${ }^{2}$ DEED-Dept ${ }^{\circ}$ Educação e Ensino a Distância - Universidade Aberta (UAb) Portugal \\ ${ }^{3}$ Departamento Administração Escolar - ADE - do Centro de Educação da \\ Universidade Federal de Santa Maria \\ maradmazzardo@gmail.com, ana.nobre@uab.pt, elena.ufsm@gmail.com
}

\begin{abstract}
In this article, the challenges are analyzed to integrate Open Educational Resources (OER) in high school. Research is parameterized by cycles of Design-Based Research by Small Open Online Course (SOOC), with 100 (one hundred) High School teachers. The results show, as a challenge, the difficulty to identify the OER repository caused by lack of information or conflicting information about licensing and copyright in the repositories and resources. Conclusively, it points out that consolidating the integration of OER, materials and the educational activities of high school, requires more disclosure practices, study and understanding of easing policies and democratization of knowledge.
\end{abstract}

Resumo. Neste artigo, são analisados os desafios para integrar Recursos Educacionais Abertos (REA) no Ensino Médio. A investigação é parametrizada pelos ciclos do Design-Based Research através de Small Open Online Course (SOOC), com 100 (cem) professores do Ensino Médio. Os resultados evidenciam, como desafio, a dificuldade para identificar os REA nos repositório, ocasionadas pela falta de informações, ou informações divergentes sobre as licenças e os direitos autorais nos repositórios e nos recursos. Conclusivamente, aponta-se que consolidar a integração de REA, nos materiais e nas atividades didáticas do Ensino Médio, requer mais divulgação, práticas, estudo e compreensão das políticas de flexibilização e democratização do conhecimento.

\section{Introdução}

Os Recursos Educacionais Abertos (REA) fazem parte do movimento da Educação Aberta, que integra também práticas educacionais abertas, dados abertos, publicações abertas e cursos de formação abertos como os Massive Open Online Course (MOOC) e as tendências emergentes, como o Small Open Online Course (Ross, 2012; Shimabukuro, 2013; Chauhan, 2014). A Educação Aberta é alavancada pelas Tecnologias Digitais de Informação e Comunicação (TDIC). No entanto, essas práticas são pouco conhecidas no contexto da Educação Básica brasileira. Com o objetivo de construir, com os professores do Ensino Médio, conhecimentos sobre REA, que 
possibilitem a sua integração nos materiais e nas atividades didáticas, organizamos o curso "REA: Educação para o Futuro", desenvolvido através de um SOOC.

A opção pelo SOOC justifica-se pela necessidade de oportunizar formação continuada, sem as barreiras de horário e localização geográfica, para os professores do Ensino Médio, os quais possuem elevada carga horária de trabalho.

Na sequência, são destacados o conceito e a caracterização dos REA, as licenças abertas, os repositórios e a identificação das licenças, os direitos autorais e os termos de uso, os procedimentos teórico-metodológicos das etapas cíclicas do Design-Based Research (DBR), a análise dos dados, os resultados preliminares e as considerações finais.

\section{Recursos Educacionais Abertos}

Os REA ou Open Educational Resourses (OER) "são materiais de ensino, aprendizagem e investigação, em qualquer suporte ou mídia, digital ou não, que estão sob domínio público ou são disponibilizados com licença aberta que permite o acesso, uso, adaptação e redistribuição gratuita por terceiros, sem restrição ou com poucas restrições" (UNESCO, 2012, p. 1). Considerando o conceito, destacamos alguns exemplos de REA: cursos completos, materiais de cursos, módulos, livros didáticos, capítulos de livros, artigos de pesquisa, testes, vídeos, recursos multimídia, animações, simulações, infográficos, mapas, recursos hipermidiáticos, imagens, músicas, áudios, jogos, software e quaisquer outros materiais para apoiar o acesso ao conhecimento.

\subsection{Caracterização dos REA}

Todos ou muitos dos recursos referidos já são utilizados pelos professores, fator que gera o questionamento: o que diferencia um REA dos outros recursos educacionais?

São as licenças abertas que permitem o acesso gratuito, o reuso, a adaptação (revisão), o remix e a distribuição sem necessidade de solicitar a permissão do detentor dos direitos autorais que diferenciam um REA de outro recurso educacional (Butcher, 2011; Santos, 2012). As licenças abertas possibilitam também a execução dos 5Rs de abertura, definidos por Wiley (2014): 1) Reter (Retain) - direito de fazer e possuir cópias dos recursos; 2) Reutilizar (Reuse) - direito de usar o conteúdo de formas variadas; 3) Rever (Revise) - direito de adaptar, ajustar, modificar ou alterar o conteúdo; 4) Remix (Remix) - direito de combinar o conteúdo original ou adaptado com outro conteúdo aberto para criar um novo recurso; 5) Redistribuir (Redistribute) - o direito de compartilhar cópias do conteúdo original, revisados e/ou remixados.

Os 5Rs de abertura ampliam as possibilidades pedagógicas dos REA. Isso porque os professores podem diversificar os materiais didáticos, adaptá-los para contextos e necessidades específicas, personalizando o ensino. O compartilhamento de REA selecionados, adaptados, remixados e produzidos, pelos professores, pode contribuir para agregar qualidade e aumentar a disponibilização de REA. Constitui-se, assim, em uma maneira dos professores fazerem parte do movimento da Educação Aberta.

Porém, essas práticas não fazem parte do cotidiano dos professores da Educação Básica, os quais precisam de incentivo, formação para conhecer e exemplos práticos dos benefícios dos REA. 
V Congresso Brasileiro de Informática na Educação (CBIE 2016)

Anais do XXII Workshop de Informática na Escola (WIE 2016)

\subsection{Licenças Abertas}

As principais licenças abertas, que caracterizam os REA, são GPL, Creative Commons e obras de Domínio Público. Vejamos suas especificações a seguir:

- GNU General Public License (Licença Pública Geral), GNU GPL ou simplesmente GPL, é a designação da licença para software livre idealizada por Richard Stallman em 1989. A GPL é a licença com maior utilização por parte de projetos de software livre (GNU GPL Wikipedia, 2016).

- As licenças Creative Commons possibilitam aos autores, de forma simples e padronizada, tornar público as permissões da obra, as quais podem ser mais abertas ou restritivas (https://br.creativecommons.org/sobre/). Ver Figura 1.

- Domínio Público: no Brasil as obras são consideradas de domínio público após 70 anos, contados de $1^{\circ}$ de janeiro do ano subsequente ao falecimento do autor, ficando livre de toda limitação de uso e recombinação, não sendo mais necessária uma licença autoral. Também são de Domínio Público as obras de autores falecidos que não tenham deixado sucessores e as de autores desconhecidos. Domínio Público significa perda dos direitos patrimoniais, sendo que os Direitos Morais continuam (Brasil, 1998).

Os recursos que são disponibilizados com termo de autorização (ou termo de cessão) do detentor dos direitos autorais, especificando o que é permitido realizar com o recurso, também podem caracterizar um REA. Esses termos são utilizados nos repositórios de recursos educacionais. Na Figura 1, apresentamos uma síntese para identificar os REA através das licenças.

CC BY SA Identificando Recursos Educacionais Abertos Através das Licenças e Autorizações

\begin{tabular}{|c|c|c|c|}
\hline Licenças e Direitos Autorais & Tipo & O que Permite? & É REA? \\
\hline \multirow[t]{7}{*}{ MOST OPEN } & CC O Domínio Público & $\begin{array}{l}\text { Distribuição (cópia), remix, adaptação e produção de } \\
\text { trabalhos derivados, mesmo para fins comerciais. }\end{array}$ & Sim \\
\hline & CCBY & $\begin{array}{l}\text { Distribuição (cópia), remix, adaptação e produção de } \\
\text { trabalhos derivados, mesmo para fins comerciais. }\end{array}$ & $\operatorname{sim}$ \\
\hline & BY SA & $\begin{array}{l}\text { Distribuição (cópia), remix, adaptação e produção de } \\
\text { trabalhos derivados, mesmo para fins comerciais com } \\
\text { compartilhamento pela mesma licença. }\end{array}$ & Sim \\
\hline & BY ND & $\begin{array}{l}\text { Permite cópia, distribuição, porém não permite obras } \\
\text { derivadas (restritiva) }\end{array}$ & Sim \\
\hline & BY NC & $\begin{array}{l}\text { Distribuição (cópia), remix, adaptação e produção de } \\
\text { trabalhos derivados. Não permite uso comercial. }\end{array}$ & Sim \\
\hline & BY NC SA & $\begin{array}{l}\text { Distribuição (cópia), remix, adaptação e produção de } \\
\text { trabalhos derivados. Uso comercial e } \\
\text { compartilhamento pela mesma licença }\end{array}$ & Sim \\
\hline & BY NC ND & $\begin{array}{l}\text { Permite cópia, distribuição, porém não permite obras } \\
\text { derivadas e uso comercial. É a licença mais restritiva } \\
\text { do Creative Commons }\end{array}$ & Sim \\
\hline & Domínio Público & $\begin{array}{l}\text { Permite cópia e distribuição (parcial ou integral), } \\
\text { edição e produção de obras derivadas, uso comercial. }\end{array}$ & Sim \\
\hline Free as in Freedom & $\begin{array}{l}\text { Licença Software Livre } \\
\text { GNU - GPL }\end{array}$ & Copiar, editar, distribuir com a mesma licença. & Sim \\
\hline $\begin{array}{l}\text { Direitos Autorais com termo de } \\
\text { cessão para uso, edição, cópia ... }\end{array}$ & $\begin{array}{l}\text { Termo de Autorização } \\
\text { do detentor dos } \\
\text { Direitos Autorais }\end{array}$ & Verificar em cada termo o que é permitido realizar & $\begin{array}{l}\text { Se permite reuso, } \\
\text { cópia e distribuição. }\end{array}$ \\
\hline
\end{tabular}

Figura1- síntese para identificar os REA através das licenças - organizada pelas autoras - Fonte das informações e imagens: http://creativecommons.org/ e https://commons.wikimedia.org

As diferentes permissões das licenças abertas e dos termos de autorização exigem atenção do usuário para identificar o REA e saber o que é possível fazer com cada recurso. A maioria dos REA disponíveis possuem licenças com uma ou mais restrições. Essa realidade impossibilita a execução dos 5Rs de abertura de Wiley (2014), 
V Congresso Brasileiro de Informática na Educação (CBIE 2016)

Anais do XXII Workshop de Informática na Escola (WIE 2016)

principalmente quando as licenças não permitem a edição do recurso e a produção de obra derivada.

\subsection{Repositórios e Identificação das Licenças Abertas, Direitos Autorais e Termos de Uso}

Os REA são disponibilizados em repositórios, portais, sites, bibliotecas digitais e blog. A saber, repositórios são sites na Web que contêm recursos digitais que podem ser utilizados na educação formal e informal (Litto, 2010). Existem repositórios institucionais (com recursos da própria instituição), multi-institucionais (armazenam recursos de mais de uma instituição), repositórios que reúnem recursos em diversos formatos e específicos para cada tipo de mídia (por exemplo: vídeo, fotos, áudios, etc.). Silva, Café e Catapan (2010) afirmam que a filosofia que norteia os repositórios é baseada no processo de colaboração e no autoarquivamento, pois são espaços que todos podem utilizar para compartilhar recursos.

A localização de licença aberta, direito autoral com termo de cessão ou termo de uso nos repositórios, não possui um padrão, e esse fator dificulta a identificação dos REA. Outro desafio é a ausência dessas informações ou informações dúbias. Amiel e Soares $(2015$, p. 3), na investigação sobre o nível de abertura dos repositórios da América Latina, a partir da análise dos termos de uso, identificaram "terminologia confusa, uso de ícones de licenciamento não padrão, a falta de clareza nas políticas de uso e o desalinho nos termos de uso entre os diferentes níveis de navegação do site".

Com base nas considerações de Amiel e Santos (2013), três orientações são sistematizadas para facilitar o acesso, pelo usuário, às informações dos termos de uso: 1) alinhamento entre os vários níveis de informação, buscando uma linguagem padrão para os termos de uso; 2) incluir as informações sobre os termos de uso no recurso; 3 ) simplificar os termos de uso utilizando linguagem clara e concisa, dando preferência para licenças conhecidas como Creative Commons. Os autores argumentam também, que, para encorajar o reuso, a adaptação, o remix e o compartilhamento de recursos, é essencial que os termos de uso dos repositórios sejam claros.

Os níveis de informação referidos na primeira orientação são os seguintes: 1) informações no termo de uso localizado geralmente no rodapé ou em um Link na primeira página do repositório; 2) dados da página intermediária, uma página de metadados com maiores informações sobre o recurso (no Portal do Professor é denominada de Ficha Técnica); 3) informações sobre as licenças no próprio recurso. Os metadados "são informações essenciais, tais como, título, autor, assunto, entre outras, que permitem buscas de informação e facilitam sua identificação, utilização, gerenciamento e compartilhamento" (Brasil, 2015).

Os professores, ao pesquisar REA, precisam identificar também o que cada licença permite, ou seja, o nível de abertura.

\subsection{Adaptação de REA}

O R de abertura Rever (Revise), de Wiley (2014), possibilita o direito de realizar alterações. Porém, para efetivar a adaptação, o recurso deve ter uma licença aberta que possibilite a edição e a produção de obras derivadas. Os REA podem ser adaptados para uma determinada realidade, para um conteúdo curricular, estilo de aprendizagem dos 
alunos, para atualizar as informações e acrescentar outros conteúdos. Enfim, realizar toda alteração que o professor considerar necessária.

Amiel e Soares (2015), na pesquisa sobre os níveis de abertura dos repositórios latinos americanos, mostram que somente $18 \%$ dos recursos possuem licenças que permitem edição (CC BY 6\%; CC BY SA 2\%; CC BY NC SA 8\%; Domínio Público 2\%). Venturini (2014), no relatório de pesquisa sobre os Recursos Educacionais Abertos no Brasil: o campo, os recursos e sua apropriação em sala de aula, no aspecto sobre licenciamento, classificou a amostra dos recursos analisados em 6 tipos, dos quais destacamos os mais abertos: flexível $22 \%$ (CC BY NC, CC BY NC SA, CC BY NC ND); livre 4,3\% (CC BY, CC BY SA, CC 0, GPL, GFDL, etc) e de Domínio Público $10,8 \%$, totalizando $37,1 \%$. Os dados das investigações evidenciam que a porcentagem de recursos que possibilitam a edição, condição necessária para adaptar/remixar, é baixa.

Para efetivar a adaptação/edição de um REA, além da abertura legal, é necessária abertura técnica, com padrões reconhecidos e formatos abertos (Amiel, Orey \& West, 2011; Amiel, 2014). Venturini (2014), também destaca a importância dos formatos abertos. Porém, na pesquisa, constatou que, nos textos disponibilizados como REA, há predomínio do formato pdf, o qual não favorece a edição e a produção de obras derivadas.

\section{Metodologia}

A investigação é desenvolvida com os procedimentos metodológicos do Design-Based Research (DBR). A DBR é uma pesquisa sistemática, flexível, realizada em contextos reais, que tem por objetivo melhorar as práticas educativas através de ciclos iterativos. É fundamentada na colaboração entre pesquisadores e profissionais, utilizando combinação de métodos e coleta de dados em várias fontes para aumentar a validade e a aplicabilidade da investigação (Wang \& Hannafin, 2005).

Implementamos um curso de 40 horas de duração, através do modelo Small Open Online Course (SOOC), denominado "REA: Educação para o Futuro". O SOOC é um curso online, com inscrição aberta, que comporta um número de alunos entre $50 \mathrm{e}$ 150, mas com acompanhamento de um professor. Downes (2013) considera 150 o número da linha de corte entre massivo e não massivo. Por conta do número de participantes no momento ser em torno de 100, classifica-se na categoria Small.

Os participantes do curso "REA: Educação para o Futuro" são professores do

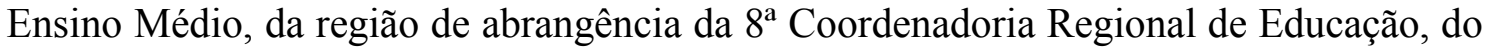
estado do Rio Grande do Sul, Brasil. Após a aplicação de um questionário diagnóstico para verificar o interesse pelo tema, a inscrição foi realizada pelos professores por adesão voluntária. As atividades, à medida em que são disponibilizadas, ficam abertas até o final do curso. Durante o ano de 2016, serão implementadas duas edições, sendo que a primeira será concluída em agosto e a segunda edição inicia em setembro de 2016.

Os conteúdos foram organizados em 4 unidades, e cada unidade compõe um ciclo iterativo. Seguindo os pressupostos da DBR, o design inicial é alterado durante o desenvolvimento do curso, em decorrência de problemas observados pelos professores e alunos, resultando no aprimoramento do material e atividades didáticas. Todos os materiais didáticos do curso são REA. 
A coleta de dados é realizada através de observação participante, análise das discussões realizadas nos fóruns, análise das atividades desenvolvidas pelos alunos e dados do questionário de avaliação do curso. Todas as atividades desenvolvidas pelos participantes são compartilhadas no ambiente do curso. Alguns dos REA selecionados/adaptados, pelos participantes e equipe de professores do curso, são divulgados e compartilhados, com outros professores e demais pessoas interessadas pelo tema, através de uma rede social (https://www.facebook.com/reanoensinomedio/).

\title{
3.1. Análise dos dados e Resultados Preliminares
}

Apresentamos a análise de três atividades desenvolvidas pelos participantes: 1) Identificar um REA; 2) Iniciar o acervo de REA; 3) Adaptar REA para integrar nas atividades didáticas. Destacam-se registros compartilhados pelos próprios cursistas durante o desenvolvimento das atividades do SOOC enquanto etapa de desenvolvimento/intervenção da DBR.

A primeira atividade foi selecionar um REA e compartilhar no fórum. Faz parte do material didático do curso um pequeno Guia sobre "Onde Encontrar REA para o Ensino Médio?" Este documento abarca sugestões de repositórios e bibliotecas digitais, mas os professores também realizaram buscas em outros espaços.

Os recursos disponibilizados com licenças Creative Commons foram mais facilmente identificados, embora, no momento de realização da primeira atividade, muitos dos participantes ainda não conseguiam identificar o significado de todos os ícones. As obras de domínio público também foram identificadas com facilidade.

\footnotetext{
"Percebi que era REA, pois fala sobre a licença Creative Commons, no final da página."

"Esse é um REA, pois está sob domínio público"
}

Os relatos evidenciam também as dificuldades encontradas:

\begin{abstract}
"Confesso que fiquei muito tempo observando e acessando os diferentes sites, pois muitas vezes o endereço do site tem licença livre, mas determinados ícones e links dentro do site não."

"Encontrei algumas dificuldades e uma delas era que estava tentando achar nos vídeos as licenças, mas depois vi que tudo o que está publicado lá tem a mesma licença."
\end{abstract}

Como na maioria dos repositórios todos os recursos estão no mesmo espaço, sem um padrão na localização das informações sobre as licenças, a identificação é mais demorada e, em alguns casos, impossível.

A segunda atividade foi iniciar o acervo de REA da área/disciplina de atuação, descrever o processo de busca, postar no fórum para discutir e compartilhar com os colegas. As avaliações indicam que foi um pouco mais fácil identificar os REA, mas que é uma atividade de demanda tempo:

\footnotetext{
"Essa tarefa proposta foi desenvolvida com mais rapidez e facilidade, pois consegui compreender melhor o que é um REA, mas ainda me sinto um pouco indecisa e insegura ao procurar os mesmos ..."

"O processo de busca não foi muito rápido, mas muito interessante, pois há uma riqueza de materiais muito grande"

"O processo de busca foi lento, porque precisava me certificar que estava realmente selecionando REAs"
} 
V Congresso Brasileiro de Informática na Educação (CBIE 2016)

Anais do XXII Workshop de Informática na Escola (WIE 2016)

"Desta experiência pude perceber que nem sempre as licenças e direitos são facilmente identificáveis."

O tempo despendido para encontrar REA e a insegurança na identificação foram destacados pelos professores. Nem todos os recursos selecionados eram REA, tema que foi discutido no fórum com questionamentos: "Como você concluiu que os recursos são REA? Ou "Conseguiu identificar a licença de cada recurso?".

A terceira atividade foi selecionar e adaptar um REA, para ser integrado em um material e/ou atividade didática. Nas orientações da atividade sugerimos iniciar com um recurso simples (como um texto), para possibilitar, a todos os professores participantes do curso, a adaptação de um REA.

Para adaptar um REA o mesmo precisa estar disponibilizado com licenças que permitam a produção de obra derivada. Alguns professores, na tentativa de adaptar um REA, não observaram os direitos autorais no uso de imagens, músicas, vídeos e textos. Não empregaram os conhecimentos sobre as licenças abertas e direitos autorais estudados. Prevaleceu a cultura da cópia, a noção de que estar disponível na Internet significa livre para uso e edição (Amiel \& Soares, 2015), e organizaram os materiais como estavam habituados. Venturini (2014) destaca a importância das licenças abertas que caracterizam os REA e ressalta que o fato de um recurso estar disponível na Internet, com acesso gratuito, não significa que é aberto. Os conhecimentos sobre as licenças abertas e direitos autorais necessitam de prática e tempo para serem incorporados.

Houve também confusão com a permissão para uso, compartilhamento e edição:

"Olha só a licença do link que eu usei. Ele é livre para uso e compartilhamento, mas deixa eu ver se entendi: não é livre para modificações. Então eu não poderia ter usado ele modificado e sim na íntegra. É isso?"

“Aos poucos estou aprendendo, não é fácil... mas é muito importante qualificarmos o nosso trabalho e buscar novos recursos para tornarmos nossas aulas mais dinâmicas e atrativas."

Os relatos apontam o percurso da apropriação do conceito de abertura e entendimento das licenças, adquiridas ao realizar a adaptação de REA. A atividade solicitada foi adaptação, mas alguns realizaram remix. A maioria dos alunos que realizaram a atividade optou pela adaptação de recursos no formato de texto.

As dificuldades observadas na análise das atividades, no ambiente do curso, também estão sendo destacadas pelos participantes na avaliação do curso, realizada através de um questionário com questões abertas e fechadas. Na questão "Qual foi a maior dificuldade para encontrar REA nos repositórios?" os termos mais citados nas respostas são identificar as licenças e (consequentemente) os REA.

Entretanto, as dificuldades para identificar os REA, não impediram a percepção dos professores sobre o potencial dos mesmos, como ilustram os dados das figuras 2 e 3 , com as respostas de 27 professores que realizaram a avaliação até o momento. 
V Congresso Brasileiro de Informática na Educação (CBIE 2016)

Anais do XXII Workshop de Informática na Escola (WIE 2016)

9 - Considerando a relevância dos materiais didáticos nas situações de aprendizagem, os REA possuem potencial que podem ser explorados para melhorar o aproveitamento dos alunos do ensino médio. (27 respostas)

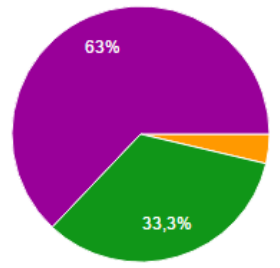

Discordo plenamente - Discordo

Não concordo nem discordo

- Concordo

- Concordo plenamente

Figura 2 - Posicionamento dos professores sobre o potencial dos REA para melhorar o aproveitamento dos alunos

A atividade de selecionar REA resultou em integração nas atividades didáticas dos professores.

Integrou REA nas suas atividades didáticas (aulas)? (27 respostas)

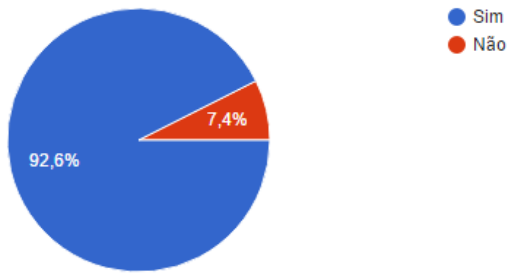

Figura 3 - Dados sobre integração de REA nas atividades didáticas

As três atividades analisadas fazem parte das unidades correspondentes que foram sendo melhoradas/redefinidas, através dos ciclos iterativos da DBR, tendo por base as discussões realizadas e dificuldades observadas em cada unidade. Como resultado os materiais didáticos do curso foram melhorados e adequados para as necessidades observadas. A Figura 1 é um exemplo. Os problemas/dificuldades e melhorias realizadas serão observadas também no design inicial da segunda edição do curso.

\section{Considerações Finais}

A primeira edição do curso está na fase final das etapas da DBR. Os resultados são preliminares, porém refletem o processo de conhecimento, identificação, seleção, organização de acervo, as primeiras experiências de adaptação/remix de REA e integração nos materiais e atividades didáticas. Os desafios foram:

1) Dificuldade para identificar os REA nos repositórios ocasionadas pela: falta de abrangência de critérios para identificar os REA nos repositórios e reutilizá-los; falta de informações sobre as licenças e direitos autorais nos recursos; divergência de licenças nos portais de acesso aos repositórios e nos recursos. Estas informações são necessárias para identificar os REA e saber o que é possível realizar com os mesmos (cópia, adaptação, remix e redistribuição). Outro fator que dificulta é a falta de cultura de observar os direitos autorais e as licenças.

Para facilitar a identificação dos REA nos repositórios sugerimos a ampliação do uso de licenças abertas padrão, como as do Creative Commons e que a licença conste no recurso. 
2) Necessidade de fluência tecnológico-pedagógica para buscar, selecionar, adaptar/remixar e organizar materiais e atividades didáticas com REA. A atividade de adaptação de REA envolve muitos conhecimentos, começando pela identificação dos REA, conhecimentos sobre software/aplicativos para editar os materiais (textos, imagens, vídeos, áudios) e redistribuir.

Durante a atividade de organização do acervo de REA, alguns professores participantes já demonstravam preocupação em como editar determinados recursos (animações, simulações), afirmando inclusive que não possuíam conhecimentos para tanto. Porém, existem recursos que não possibilitam a edição pelos professores, não somente por falta de fluência com as tecnologias, mas também por falta de abertura técnica dos recursos.

Adaptar REA foi uma atividade mais complexa e o número de participantes foi menor, fato que confirma os resultados internacionais na oferta de cursos online abertos como os SOOC ou MOOC, persistindo o desafio de encontrar estratégias para aumentar a participação em todas as atividades.

Conclusivamente, aponta-se que consolidar o reuso, adaptação, remix, produção, compartilhamento de REA e integração nos materiais e nas atividades didáticas do Ensino Médio, requer mais divulgação, estudo, práticas e compreensão das políticas de flexibilização e democratização do conhecimento.

\section{Referências}

Amiel, T.; Orey, M. \& West, R. (2011). Recursos Educacionais Abertos (REA): modelos para localização e adaptação. In ETD - Educ. Tem. Dig., Campinas, v.12, n.esp., p.112-125, mar. 2011 - ISSN: 1676-2592. Retirado de https://www.fe.unicamp.br/revistas/ged/etd/article/view/2284

Amiel, T. \& Santos, K. (2013). “Uma análise dos termos de uso de repositórios de recursos educacionais digitais no Brasil”. Revista Trilha Digital, São Paulo, v. 1, p. 118-133, 2013. Retirado de http://editorarevistas.mackenzie.br/index.php/TDig/article/download/5892/4253

Amiel, T. (2014). "Recursos Educacionais Abertos: uma análise a partir do livro didático de história”. In: Revista História Hoje, v. 3, no 5, p. 189-205 - 2014. Retirado de https://rhhj.anpuh.org/RHHJ/article/view/128

Amiel, T. \& Soares, T. C. (2015). "Um método para auditoria de repositórios abertos com resultados da América Latina". In: Anais da X Conferência Latino-Americana de Objetos e Tecnologias de Aprendizagem (LACLO 2015). Retirado de

http://www.br-ie.org/pub/index.php/teste/article/view/5784

Brasil. (1998). Lei Direitos Autorais No 9610/98. Retirado de http://www.planalto.gov.br/ccivil_03/leis/L9610.htm

Brasil. (2015). Ministério da Saúde. Secretaria de Gestão do Trabalho e da Educação na Saúde. Universidade Aberta do Sistema Único de Saúde. "Manual de descrição e preenchimento de metadados" / Universidade Aberta do Sistema Único de Saúde. 3. ed. - Brasília : UNA-SUS, 2015. Retirado de https://ares.unasus.gov.br/acervo/static/files/Manual_ARES_UNASUS.pdf 
V Congresso Brasileiro de Informática na Educação (CBIE 2016)

Anais do XXII Workshop de Informática na Escola (WIE 2016)

Butcher, N. (2011). "A Basic Guide to Open Educational Resources”. British Columbia/Paris: COL e UNESCO, 2011. Retirado de http://unesdoc.unesco.org/images/0021/002158/215804e.pdf

Chauhan. A. (2014). "Massive Open Online Courses (MOOCS): Emerging Trends un Assessment and Accreditation". In Digital Education Review, No 25 Junho, 2014. Retirado de http://revistes.ub.edu/index.php/der/article/view/11325

Downes, S. (2013). "What makes a MOOC massive" [Blog post]. Half an Hour, 2013. Retirado de http://halfanhour.blogspot.com.br/2013/01/what-makes-mooc$\underline{\text { massive.html }}$

Litto, F.M. (2010). “Aprendizagem a Distância”. Ilustração Paulo Caruso. São Paulo: Imprensa Oficial do Estado de São Paulo, 2010.

Ross, H. (2012). "Instead of a MOOC, How About a SOOC?" Retirado de http://words.usask.ca/gmcte/2012/10/29/instead-of-a-mooc-how-about-a-sooc/

Santos, A. I. dos. (2012). "Educação aberta: histórico, práticas e o contexto dos recursos educacionais abertos". In: Recursos Educacionais Abertos: práticas colaborativas políticas públicas / Bianca Santana; Carolina Rossini; Nelson De Lucca Pretto (Org.). - 1. ed., 1 imp. - Salvador: Edufba; São Paulo: Casa da Cultura Digital, 2012. 246 p. Retirado de http://www.artigos.livrorea.net.br/

Shimabukuro, J. (2013). "SPOCs Are MOOC Game Changers." In Educational Technology and Change Journal. 2013. Retirado de https://etcjournal.com/2013/09/26/spocs-are-mooc-game-changers/

Silva, E. L. D.; Café, L. \& Catapan, A. H. (2010) "Os objetos educacionais, os metadados e os repositórios na sociedade da informação”. Ciência da Informação, v. 39, p. 93-104, 2010. Recuperado de http://www.scielo.br/pdf/ci/v39n3/v39n3a08.pdf

UNESCO. (2012). "Declaração REA de Paris. UNESCO, 2012. Retirado de http://www.unesco.org/new/fileadmin/MULTIMEDIA/HQ/CI/CI/pdf/Events/Portugu ese Paris OER Declaration.pdf

Venturini, J. (2014). "Recursos educacionais abertos no Brasil: o campo, os recursos e sua apropriação em sala de aula." / Vol. 11. - São Paulo : Ação Educativa, 2014. 64p. ISBN: 978-85-86382-37-6. Retirado de http://www.acaoeducativa.org/images/stories/pdfs/EmQuestao11_site.pdf

Wang, F., \& Hannafin, M. J. (2005). Design-based Research and Technology-Enhanced Learning Environments. ETR\&D, 53(4), pp. 5-23. Retirado de https://ideascale.com/userimages/sub-1/898000/panel_upload_12279/30221206.pdf>

Wiley, D. A. (2014). “The Access Compromise And The 5th R”. 2014. Retirado de http://opencontent.org/blog/archives/3221

Wikipédia. (2016). “GNU General Public License.” Retirado de https://pt.wikipedia.org/w/index.php?title=GNU_General_Public_License\&oldid=44 $\underline{846246}$ 